\title{
APPLICATION OF 3D PRINTING IN INNOVATED DRUG DELIVERY: A REVIEW
}

\author{
ZAINAB EASSA JASSIM* \\ ${ }^{*}$ Department of Pharmaceutics, College of Pharmacy, University of Baghdad, Iraq \\ *Email: zainabeassa@yahoo.com
}

Received: 09 Apr 2021, Revised and Accepted: 09 Jun 2021

\begin{abstract}
Increasing requests for modified and personalized pharmaceutics and medical materials makes the implementation of additive manufacturing increased rapidly in recent years. 3D printing has been involved numerous advantages in case of reduction in waste, flexibility in the design, and minimizing the high cost of intended products for bulk production of. Several of 3D printing technologies have been developed to fabricate novel solid dosage forms, including selective laser sintering, binder deposition, stereolithography, inkjet printing, extrusion-based printing, and fused deposition modeling. The selection of 3D printing techniques depends on their compatibility with the printed drug products. This review intent to provide a perspective on the incentives and possible applications of 3D printed pharmaceuticals, besides a practical viewpoint on how 3D printing could be included across the pharmaceutical field.
\end{abstract}

Keywords: Three-dimensional printing, Fused deposition modeling, Pharmaceutical application, Levapiracetam and personalized medicines

(C) 2021 The Authors. Published by Innovare Academic Sciences Pvt Ltd. This is an open access article under the CC BY license (https://creativecommons.org/licenses/by/4.0/) DOI: https://dx.doi.org/10.22159/ijap.2021v13i4.41741. Journal homepage: https://innovareacademics.in/journals/index.php/ijap

\section{INTRODUCTION}

Nowadays, three-dimensional printing (3DP) has become one of the most innovative and fastest developing branches of technologies in the pharmaceutical field. 3D printing contributes to significant advances and serving as a technology of accurate fabrication of individually developed dosage forms, tissue engineering, and disease modeling [1]. 3D printing can meet an important role in multiple active ingredient dosage forms, where the formulation can be as a single-blend or multi-layer printed tablet with a sustained release pattern. This reduces the frequency and number of dosage form units consumed by the patient on a daily routine [2].

3D printing or additive manufacturing is a rapid prototyping technology that prints 3D objects by a layer-by-layer deposition approach controlled by software called computer-aided design [3, 4]. 3D printing has been used to design "complex structures", which are very challenging to manufacture with traditional methods [5]. It has been considered in different applications especially medical and pharmaceutical applications such as tissue engineering, dentistry, and implants. In August 2015, Food and Drug Administration (FDA) approved the application of 3D printing in the pharmaceutical industry showing that $3 \mathrm{D}$ printing might elaborate its great assistances in personalized medicine and in the fabrication of tablets with different structures and materials that have distinguished release profiles [6]

These technologies and the related advantages enable the researchers to improve existing medical applications that use 3Dprinting technology and to explore new ones. The point of 3D printing that has been already reached in medicine is significant and exciting, but some of the more revolutionary applications, such as bio-organ printing, need more time to evolve.

The principle of this technology depends on the transformation of materials into prototypes by taking help from 3D computer-aided design (CAD) files, hence digitally controlled and a customized product can be fabricated [7]. Three-dimensional printing is a layerby-layer fabrication of $3 \mathrm{D}$ objects from digital designs; it is a relatively novel technique and was first described in the early 1990 s for rapid prototyping, which builds solid objects by deposition of numerous layers in series. This technology developed more than 30 $\mathrm{y}$ ago for the construction of models from UV-cured resins and originated as a result of combined research of chemistry, optics, and robotics [8]. Therefore, other terminologies were used to define 3D printing such as layered manufacturing, additive manufacturing, computer automated manufacturing, rapid prototyping, or solid freeform technology.
The main object behind discovering and using 3D printing techniques is to design and develop medicines that are well-matched to an individual's needs. In this approach, we can easily adjust the size, appearance, shape, and rate of delivery of a wide array of medicines.

\section{Starting point of 3D printing}

3D printing technology first becomes evident in 1984, when Charles Hull invents the Stereolithography technique; a 3D printing method that utilizes UV light to generate a 3D object by building up layer after layer, Charles Hull became the co-founder of 3D systems [9]. The first stereolithography apparatus was sold in 1988. In 1989, One of today's prominent additive manufacturing technologies was developed by Scott Crump, who produced a patent on another 3D printing technology which is "fused deposition modeling" [10, 11] Emanuel Sachs-MIT scientist patented with co-workers threedimensional printing techniques based on linking of the selected regions of powder by binding material [12]. In 1992, 3D printing was evolved to introduce a large development in 3D system as two 3D printers were developed in this year, SLA "stereolithographic apparatus" 3D printer and SLS "selective laser sintering" 3D printer machine [13]. During the last few decades, numerous 3DP technologies have evolved and been utilized in abundant fields either to advance the functionality of the existing system or as a new manufacturing process [14].

\section{Advantages and limitations of 3D printing}

\section{Advantages}

Application of the 3D printing processes mainly in the oral dosage form production has many advantages especially for customizing drug delivery. The medicine can be involved in the dosage form as per each patient necessity to achieve a personalized dose and release pattern [15]. 3D printing aids also in achieving multidrug combinations with complex release profiles. On-request production and printed products with specific geometries, designs, and shape forms can be attained which otherwise would be difficult with conventional tableting.

Many advantages can be offered from 3D printing including the ability to produce dosage forms with complex drug release profiles by accurate control of droplet size and dose with high reproducibility. This technology makes complex drug manufacturing processes more standardized, simpler, and more practical. Such advanced technology allows drug dosage forms, release profiles, and dispensing to be customized for each patient. "Precision drug dispensing" is the principle by which drugs are actually 
manufactured by $3 \mathrm{D}$ printing. The drugs themselves could be tailored to meet various precise specifications and address the unique needs of individuals taking them. At the same time, there has been excessive research to summarize the 3D printing disadvantages, this new technology has still some limitations [16].

\section{Limitations}

- Nozzle problems are a major challenge as discontinuing of the print head affects the structure of final products.

- Powder printing blocking is another obstacle.

- Probability of altering the finishing structure on to mechanical stress, storage condition adaptions, and the effects of ink formulations.

- Printer-related parameters and these effects on printing quality and printer cost [17]

Optimization of the process, improving the performance of the device for versatile use, selections of appropriate excipients, posttreatment method, need to be addressed to improve the 3D printed products performance and to expand the application range in novel drug delivery systems are the most challenges in the application of 3 D printing. Few 3D printing techniques may produce relatively porous structures and uneven shapes of dosage forms. For example, when the fused deposition modeling technique is utilized, the use of only thermo-stable drugs and the few available compatible excipients is a regulating step. Also, with stereolithography, the challenge lies in the possible drug degradation due to the exposure of materials to UV light that induces polymerization reaction [18].

In terms of technological hurdles, and comparison, to traditional manufacturing methods, the major shortcoming of all 3D printing methods is its yield of production. While a conventional tableting process can produce more than 15000 tablets per minute using one press, the production time for 3D printing can vary from an average of $2 \mathrm{~min}$ up to $2 \mathrm{~h}$ (depending on the process used) to produce just one tablet. Even though this limitation may hinder industrial production, one can argue that the greatest strength of 3D-printed pharmaceutical products is the possibility of bringing production closer to the patient, which means printing on a small scale locally in pharmacies or hospitals. Other general problems that may arise in most 3D printing methods include the variability in layer thickness, the relatively limited material choices, as well as the presence of unreacted starting-material in the final formulation [19].

\section{Types of 3D printing technologies}

Varieties of 3DP methods are produced to fabricate diversities of pharmaceutical dosage forms, many factors are affecting on the development of 3D printed subject like an energy source, material source, and other mechanical characters.

\section{Thermal ink-jet printing}

In thermal inkjet printing (TIJ), the principle of this technique can be summarized as the aqueous ink fluid is converted to vapor form through heat and expands to push the ink drop out of a nozzle (fig. 1). The application of TIJ was involved in the preparation of drugloaded biodegradable microspheres, drug-loaded liposomes, patterning microelectrode arrays coating, and loading drug-eluting stents. It is considered an efficient and practical method of producing films of biologics without compromising protein activity. The main advantage of injecting printing method in the pharmaceutical application is its high accuracy in creating 3D drug products $[20,21]$. One of the disadvantages of TIJ is the high temperature applied may potentially lead to degradation of heatlabile active ingredients and excipients which limits its pharmaceutical use $[22,23]$.

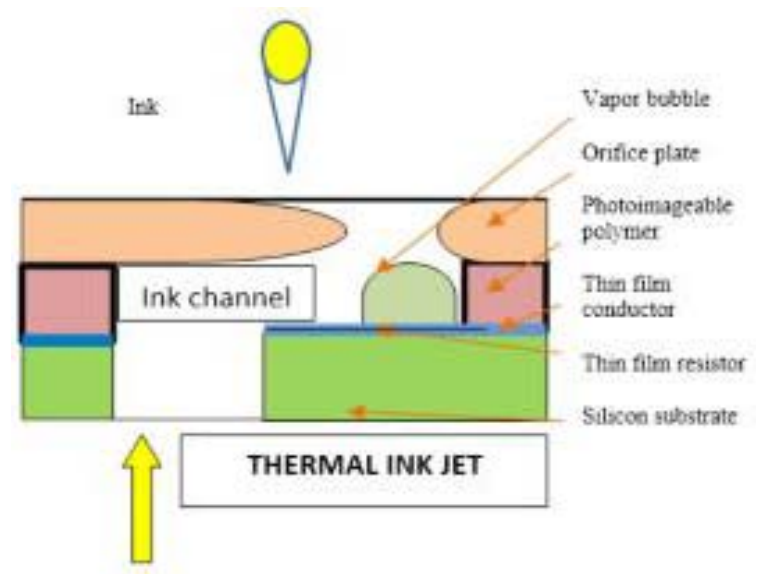

Fig. 1: Thermal inkjet printer technique [20]

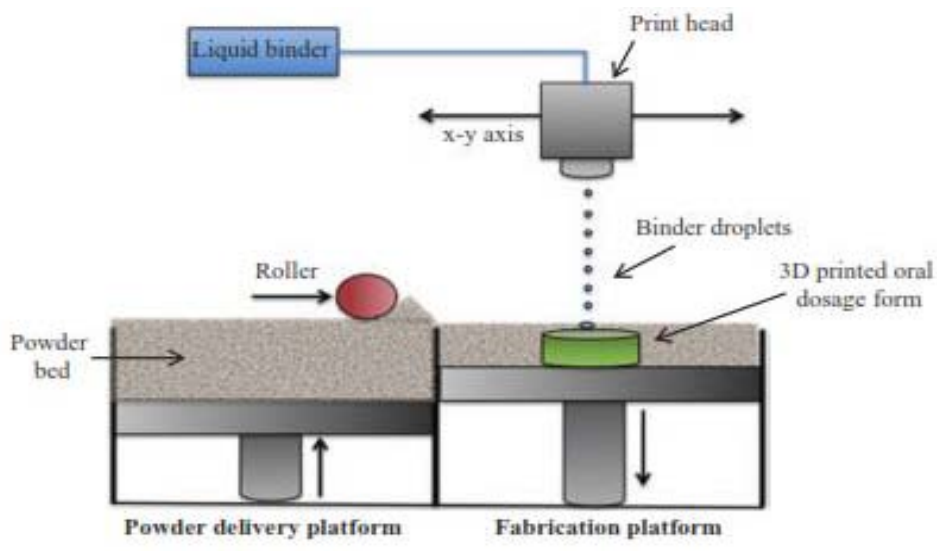

Fig. 2: Binder jet printing [24] 


\section{Binder jet 3D printing}

In 1993 Sachs et al. invented and patented binder jet printing at the Massachusetts Institute of Technology (MIT). Binder jet printing, also known as a drop-on-powder method, is an application of inkjet printing technology. The main part of a binder jet printer is the print head, which can either be thermal or piezoelectric. Binder jet printer constitutes of a powder bed that is joined in a layer-wise fashion. A printer nozzle that contains the binder (and/or drug) fluid is programmed to jet the liquid onto the loose powder bed by moving along an $x-y$-axis [24]. The powder is in turn moistened by the liquid drops which lead to hardening and solidification of the layer as shown in (fig. 2). The powder solidification occurs either by forming binder bridges or by the dissolution and recrystallization of particles. The fabrication platform then will move downwards across the z-axis while the powder delivery platform moves up. A roller then moves a powder layer from the bed to the top of the formerly bound layer. This procedure is repeated successively and the 3D object is constructed [25].

The binder jet printing process is based on conventional ink-jet printing technology and involves five main steps as shown in fig. 3.

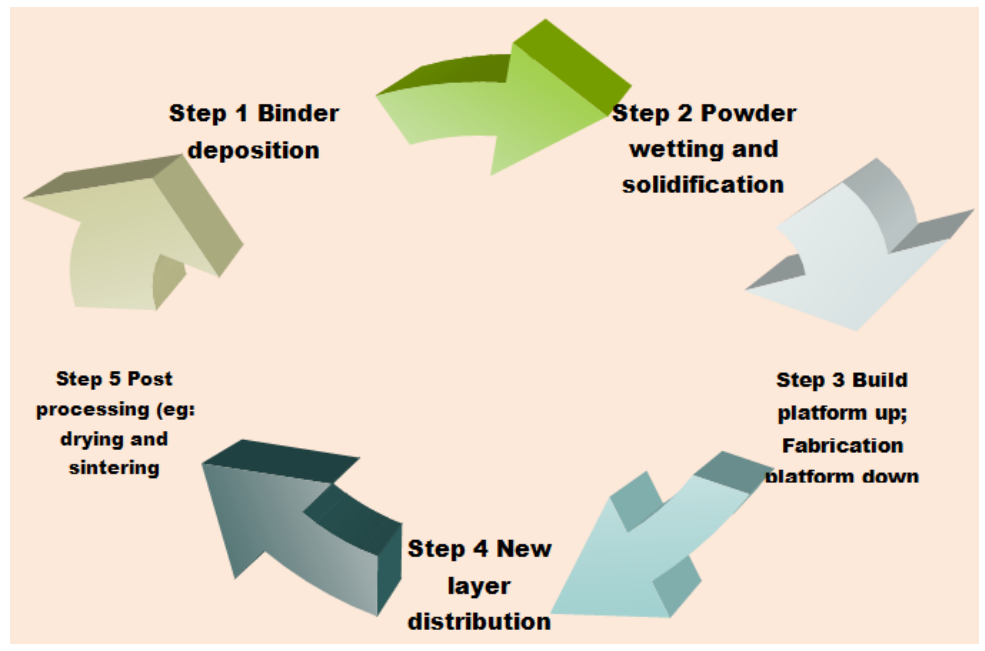

Fig. 3: Binder jet printing process steps [53]

\section{Fused deposition modeling (FDM)}

FDM consumes thermoplastic polymers such as polyvinyl acetate (PVA) in a semi-molten form rather than a powder bed. In this method, the principle involves the passing of thermoplastic materials down between two rollers to the nozzle tip where it will be subsequently extruded (fig. 4). Before extrusion, the materials are heated by a temperaturecontrolled condition to ensure their semi-molten form during the extrusion process. Then, the semi-molten polymers harden, the printing platform is lowered and the same process is repeated until the desired $3 \mathrm{D}$ object is achieved [26, 27]. Due to the polymer nature of the filaments, they exhibit considerable structural stability after printing and solidifying. These filaments are also largely water-soluble and are capable of being loaded with a drug in solution. The filament can be loaded with variable concentrations of drugs for specified doses by dissolving the drug in an ethanolic solution and immersing the unprinted, solid filament in the solution [28]. This method can be used for manufacturing solid dosage forms such as zero-order release tablets, multi-layered tablets, fast-dissolving tablets. Fused deposition modelling technique was used to fabricate a tablet of prednisolone-loaded poly vinyl alcohol (PVA) filaments with extended-release [29].

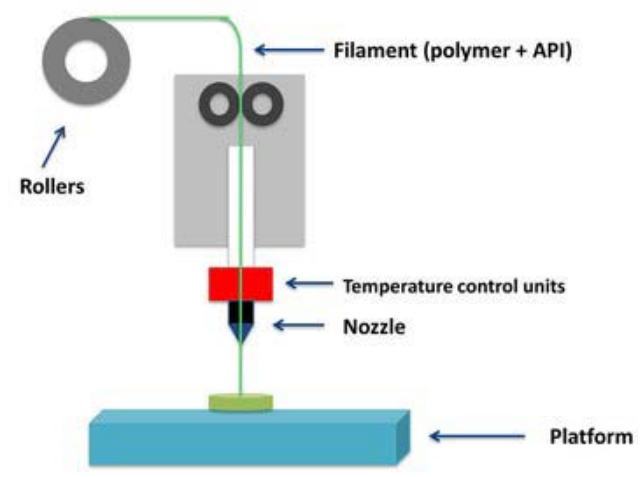

Fig. 4: Fused deposition modeling (FDM) [69]

\section{Pressure-assisted microsyringe (PAM)}

It can be considered that there is the similarity between "PAM" method and "FDM", with the only difference in which there is no need for melting of materials in PAM method. The principle of PAM is depending on using a syringe to release viscous semi-liquid material to produce the desired and optimum 3D model [30] as shown in (fig. 5). PAM 3D printer system is used to design and substantialize the diverse construction of 3D models. In this advanced technology a computer-controlled microsyringe was exploited providing the desired structure and the release of the dissolved polymer will be under consistent and low pressure. The following processes after designing include drying and solidification that give sufficient physical strength for dosage form [31].

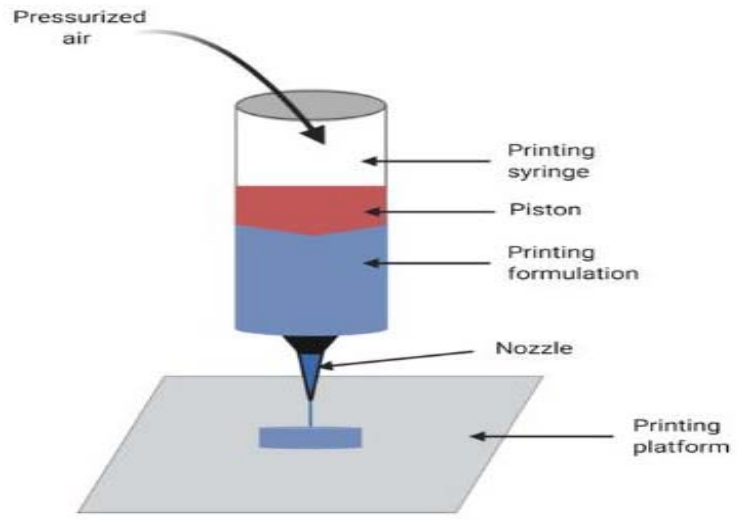

Fig. 5: Schematic of a pressure-assisted microsyringe [25]

\section{Hot-melt extrusion (HME)}

Recently hot-melt extrusion (HME) was the main way of producing active pharmaceutical ingredient-loaded filaments. Drug 
amalgamation in the HME method involves pelletizing and grinding of commercially available filaments mixed with active ingredient(s) before a hot melt re-extrusion (fig. 6). The grinding process is important as it ensures that the API (powder) and polymer have similar particle sizes. Mixing pellets with drug powder would lead to poor encapsulation and subsequently poor drug loading [32].

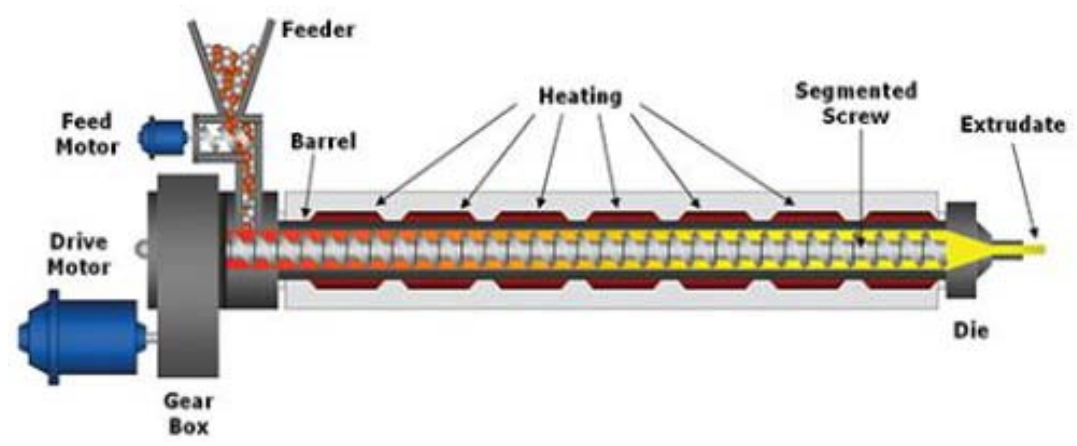

Fig. 6: Hot melt extrusion techniques in 3D printing [32]

\section{Stereolithography (SLA)}

SLA is another promising technology for the fabrication of drugloaded tablets. This method involves exposing a photopolymerisable resin to high-energy light (e. g. UV light) to induce polymerization and solidification of the material. Each time, the resin is solidified to a defined depth, the platform is moved down vertically along the $\mathrm{z}$ axis, the built layer is recoated with resin and the process is repeated layer-by-layer (fig. 7) [33]. This technology has been widely applied to tissue engineering [34] and has more recently been applied to pharmaceutical applications. For example, Wang et al. fabricated modified-release tablets containing 4-aminosalicylic acid (4-ASA) and paracetamol using SLA. Furthermore, SLA uses lower localized temperatures (e. g. compared to fused deposition modeling and SLS), being more suitable for thermally labile APIs. However, there are safety concerns with SLA as the commercially available resins and photoinitiators contain functional groups that may exhibit cytotoxicity [35].

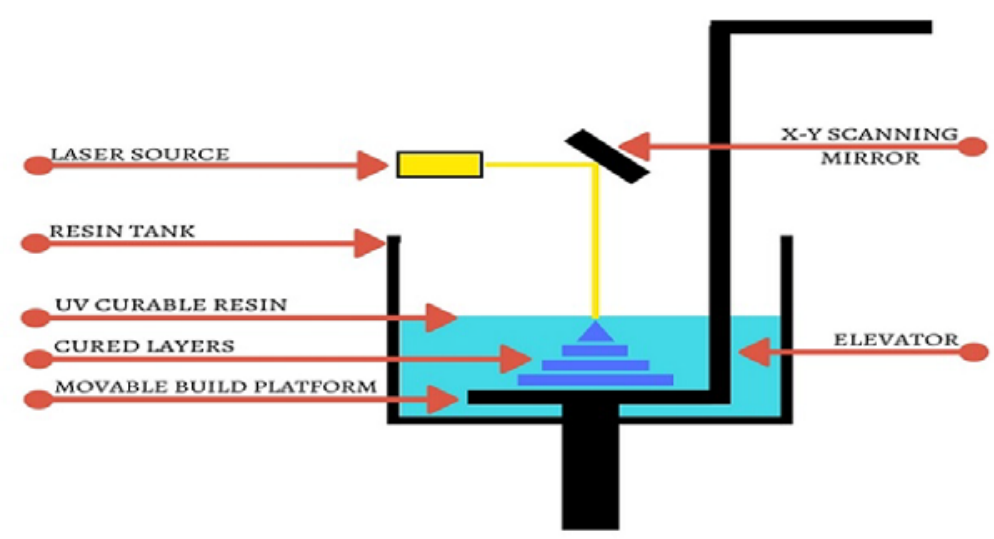

Fig. 7: Demonstration of the working of stereolithography technology [34]

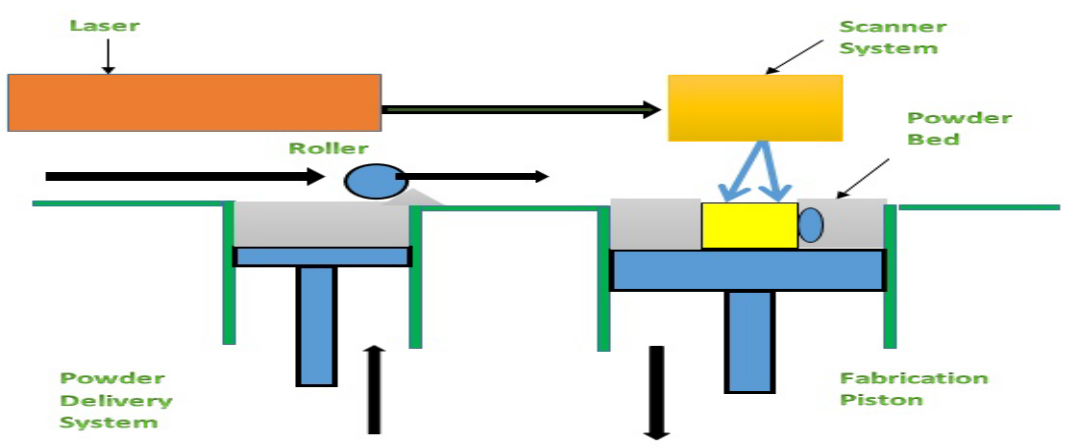

Fig. 8: Demonstration of the working of selective laser sintering technology [37]

\section{Selective laser sintering (SLS)}

Selective laser sintering (SLS) is another method of 3D printing, the most recent and most advanced technologies recommended for the preparation of solid dosage forms [36]. SLS is composed of a onestep manufacturing process involving a laser to selectively sinter powder particles in a layered manner to form 3D configurations. The structure of SLS printer mainly consists of a powder bed, a powder 
reservoir, a roller, and a laser source. The powder for printing is equivalently spread on the powder bed by the roller. Based on the 3D design of the object, the laser is focused to draw specific patterns on the powder surface sintering and agglomeration of the powder particles. Once the first layer is sintered, the powder bed moves down while the reservoir bed moves up to allow for the delivery of a new layer of powder on top of the previous one as demonstrated in (fig. 8). At first, the method was deliberated to print objects at high temperatures using metallic, ceramic, or thermoplastic materials like PA12 (Nylon) or PEEK (Polyether ether ketone) [37]. Temporarily, SLS printing technology was not considered suitable for the fabrication of 3D printed medicines due to the potential degradation of the drugs caused by the high energy of the $\mathrm{CO}_{2}$ lasers that work in the Infrared (IR) region of the spectra. Currently, however, lower intensity diode lasers have been used in SLS printers, and make it possible to formulate novel drug products with no drug degradation [38].

\section{Digital light processing (DLP)}

In 1986 digital light processing is first described by Charles, a method that prints many layers by ultraviolet light to create 3D structures. The digital light processing technology is employing projection light to polymerize materials to obtain the predesigned structures (fig. 9). In comparison with other 3D printing methods, such as extrusion-based 3D printing methods and inkjet-based 3D printing methods, this method has significant compensations in printing resolution, efficiency, and working conditions. Hence, it can give many good features to the products [39, 40]. Photopolymerization processes utilize liquid photo-curable resins, which undergo chemical reactions upon irradiation with light and fabricate solid objects, DLP uses a projector to selectively expose and cure an entire cross-sectional slice of the photopolymerizable resin at each given time [41].

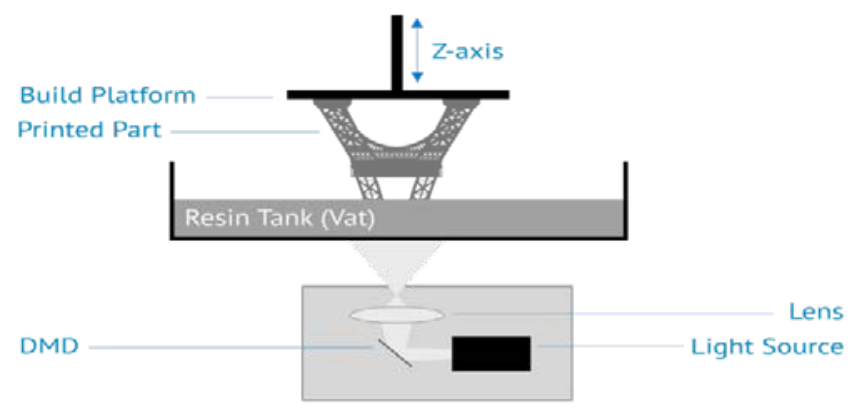

Fig. 9: A schematic of a DLP 3D printer [39]

\section{Printing-based inkjet (IJ) system}

Printing-based inkjet II system is one of the 3D printing methods consist of two kinds of technologies, to be precise, continuous inkjet printing (CIJ) and drop-on-demand printing (DOD) as shown in fig. 10.

- Continuous inkjet printing (CIJ) incorporates pressure to drive the 'ink' liquid towards the nozzle tip for extrusion (fig. 10a). A charged deflector at the nozzle tip attends to control the extrusion of 'ink' liquid either towards the printer stage for printing or waste chamber for recycling and reprocess on the next printing [42].
- Drop on Demand (DoD) can be additionally categorized into two types, which are thermal and piezoelectric. For thermal printing (fig. $10 \mathrm{~b})$, the electrical pulse generates a rapid rise of heat to form a vapor bubble in the ink reservoir. The bubble then drives the 'ink' out of the reservoir and onto the substrate before it collapses, thus producing negative pressure in the ink reservoir. The negative pressure causes any unused ink to refill the ink reservoir. As heat is utilized in this process, the material used as 'ink' must be non-volatile. DOD is more advantageous than $\mathrm{CJ}$ as it is less wasteful and more precise, whereby it can extrude ink volume as low as 1-100 pl per drop [43]. a

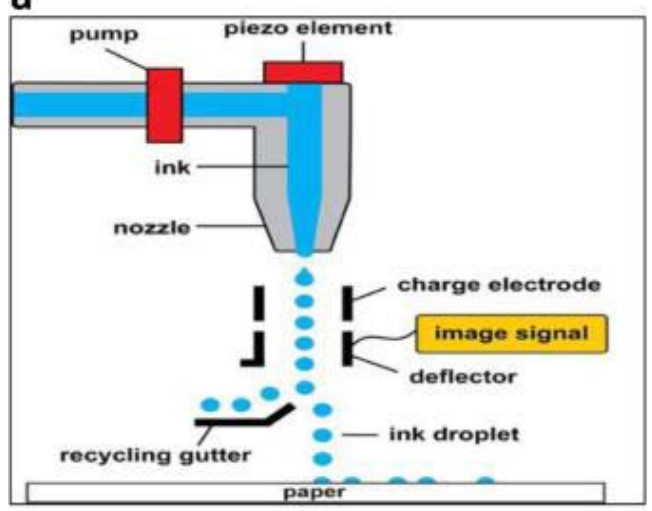

b

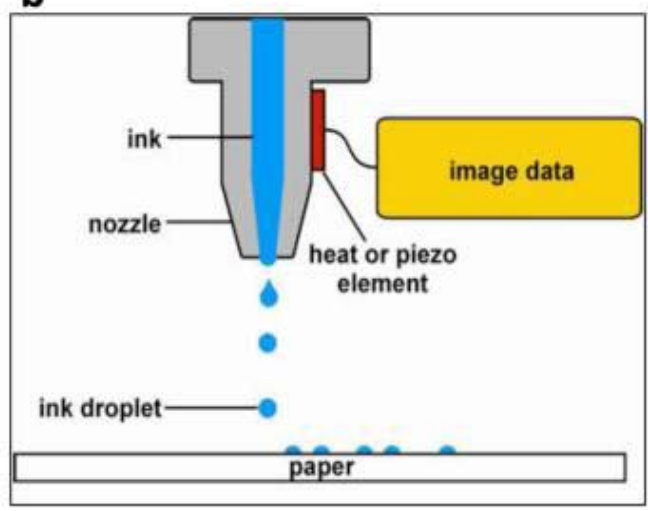

Fig. 10: Inject printing technique (a) continuous (CIJ), (b) drop on demand (DOD) [16]

\section{Embedded 3D printing (e-3DP)}

Embedded 3D printing is a developed method of $3 \mathrm{D}$ printers where semi-solid materials are extruded into a solidifying reservoir using a deposition nozzle at a predetermined route. Chewable oral dosage forms were the first examples in the pharmaceutical field presented by
Rycerz et al., in using embedded 3D printing to fabricate with dual drug loading. The two drugs used were paracetamol and ibuprofen, which were suspended in locust gum solution and an embedding medium of gelatin-based matrix material. These were printed at an elevated temperature of $70{ }^{\circ} \mathrm{C}$ and then solidify at room temperature $[44,45]$. The factors affecting on dosing of the printed dosage forms 
were varied by specifically altering the printing patterns. The rheology, printing speed, and the needle size of the embedded phase were also inspected. Several reports have shown the potential of e3DP to be used to print oral dosage forms that could include various materials, allow this method to be a suitable technology for personalized pediatrics novel dosage form [46].

\section{Application of 3DP technology to pharmaceutical dosage forms}

Pharmaceutical applications for 3D printing are escalating rapidly and are expected to revolutionize health care; 3D printing technologies are already being used in pharmaceutical research and fabrication. In this review, we discussed the most pharmaceutical areas in which 3D printer technologies are used, for example, oral solid dosage forms, transdermal delivery systems, and other delivery that seem to be experiencing relatively greater progress and are more suitable for wide applications of 3DP.

The summary of the application of 3-dimensional printing technologies is shown in table 1 .

\section{Personalized medicines}

Since the discovery of the Precision Medicines Initiative in the USA in 2015, there has been increased emphasis on moving medical and clinical treatment away from a 'one-size-fits-all approach toward personalization. Conventional tablets are mass manufactured in a few distinct strengths, often based on the dose required to produce its therapeutic effect in the majority of the population. However, it is evident that one dose might not fit all; requirements can vary based on a patient's genetic profile, disease state, and other factors (e. g. gender, age, and weight) [47]. The field of personalized medicine requires understanding on how tailoring therapies to a patient based on their individual features, needs, and preferences. 3D printing can offer potential in achieving flexibility of doses according to the patient's needs $[15,48]$.

Accuracy, safety, and the potential for customization are the most benefits of 3D printed personalized medicines [49]. 3D printed pellets or mini-prints, which are mini-tablets, have been developed, and these can be personalized. They can also be used to combine two different drugs [50]. Mini-printlets can also be combined and encapsulated according to the dose necessary to achieve personalization [51].

\section{Spritam $\AA$ : the first FDA approved 3D printed product}

Spirtam ${ }^{\circledR}$ (levapiracetam) is the first 3D printed prescription drug tablet to treat partial-onset seizures, myoclonic seizures, and primary generalized tonic-clonic seizures produced by Aprecia Pharmaceuticals (the first pharmaceutical which started to incorporate 3D printing in one of its products) and approved by Food and Drug Administration in August 2015[52]. The powder bed binding technique was utilized to produce a complex, pyramidshaped, and immediate-release 3D tablet without applying compression. This 3D printed tablet is characterized by a highly porous framework even at high doses, $1000 \mathrm{mg}$ of active pharmaceutical ingredient, permitting fast disintegration in the patient's mouth with a little amount of water. The new 3D tablet compromises the benefit of reducing the lag time for the onset of action since a large proportion of the drug is presented for absorption via the oral mucosa into the general circulation. Also, this kind of formulation can open up a new way of designing dosage forms for patients who struggle to swallow a tablet $[12,17,53]$.

\section{Pediatric-printed tablets}

A novel 3D printed designs such as minitablets and chewable dosage forms were established to serve the need for appropriate pediatric oral formulations with flexible dosing and easy administration. Formerly, FDM 3D printing technology was used to prepare baclofen mini caplets [54] and indomethacin pediatric dosage forms with a Starmix ${ }^{\circledR}$ design demonstrating suitable taste masking properties [55]. Besides, pediatric-pleasant chewable formulations were also developed using extrusion-based 3D printing technology, including Lego $^{\mathrm{TM}}$-like tablets and chocolate-based dosage forms, overcoming the issue of swallowability and hence improving treatment adherence in children [45]. At first, Goyanes et al. reported the manufacturing of isoleucine, for the treatment of a rare metabolic disease, into chewable formulations by using semi-solid extrusion 3D printing technology in a clinical location, letting the small-batch production of medicines at the point of dispensing [56]. This was the first and only study so far that successfully probed the use of 3D printing in a hospital setting to prepare treatments at the dispensing point.

\section{D printing and controlled release drug}

3D printing can adjust the shape and internal structure of the tablet by selecting materials, setting parameters, and designing models. It can control the release rate or the time of the drug because the printed tablets' release curve is linked to the shape of drugs [57]. According to pharmacokinetics, drug release is directly proportional to the ratio of surface area to volume, thus indicating that geometrical design can affect the release profile. The costumed shape created by 3D printing changes the surface area of the pill, which can control the strength and time of the drug release [58]. Liang et al. used 3D printing technology to manufacture oral drug delivery devices with adjustable release rates, and the device appeared in the form of dental braces. They then evaluated the device's performance in local environments, demonstrating the feasibility of a 3D-printed drug delivery system in humans [59].

\section{Complex drug-release profiles}

Formulation of medications with complex drug release characteristics is one of the most explored or studied uses of this novel technology. Several research groups have formulated tablets with different release profiles like immediate, sustained, or delayed release by changing polymer type and amount, tablet filling density, and tablet shape $[60,61]$. Khaled et al. formulated sustained-release tablets of guaifenesin by 3D printing technology with an identical release profile of standard commercial tablets which are able to satisfy regulatory tests. Hydroxypropyl methylcellulose and polyacrylic acid were utilized as a hydrophilic matrix for manufacturing a sustained release layer. A comparable drug release profile was obtained as that of a commercial guaifenesin bi-layer tablet $[62,63]$.

\section{D printed hollow structure tablets}

A novel enabling strategy to increase the solubility and bioavailability of the poorly soluble drug with 3D printing technique. Fused disposition method was used to formulate a gastro-retentive system with an extended-release design. The advanced 3D tablet represented a new concept as a using the. Domperidone was used as a model medicine and loaded onto a hydrophilic carrier of hydroxypropyl cellulose (HPC) filament as solid dispersion and printed into a hollow structure tablet. The shape of the hollow structure was controlled with two main factors including the numbers of shell and infill percentage which may affect the outline and inner part of the 3D object, respectively. Increasing the number of shells will add the weight and strength of the tablet. On the other hand, reducing the infill percentage during the printing leads to increased porosity of the tablet, thereby improving the dissolution rate $[8,64]$.

\section{Oral dispersible high-dose medications}

Oral dispersible low and even high-dose medications up to $1000 \mathrm{mg}$ can be designed by 3D printing technology without using compression forces or traditional molding techniques. A 3D printer which it calls ZipDose stitches up together multiple layers of powdered medication with the help of aqueous fluid to yield a porous, water-soluble matrix that rapidly disintegrates with a little volume of liquid [65].

\section{D printed implants}

An implant is a drug delivery structure containing one or more than one active pharmaceutical ingredient loaded for continuous delivery to the targeted tissue, giving advantages to patients who need longterm treatment of medications. While the predictable approach for implant progression was mainly directed on expanded and delayed drug release, late 3D printing-based inserts are intended to have a complex matrix and large scale structures in a solitary device, for multi APIs stacking and accomplishing more advanced drug 
discharge characteristics. 3D printed implants were effectively established utilizing different technologies, like powder bed fusion technology, in designing rifampicin, levofloxacin implants based on the lactic acid polymeric matrix [66].

\section{Personalized topical medication}

Studies of 3D printing in topical drug delivery systems occupy a small area in pharmaceutical application. Stereolithography (SLA) is a more appropriate 3D printing method for the production of masks than FDM due to faster diffusion, higher drug loading capacity, higher resolution, and no drug degradation. This method produced a nose-shaped device that was determined as a feasible method to treat acne. SLA 3D printing has also successfully been used to produce silicone casts of the nasal cavity and sinus of a patient with chronic rhinosinusitis to improve the delivery of topical medication into the sinus cavities during the sinus surgery [67].

\section{Designing of 3D printed polypill}

The concept of-polypill refers to a single tablet that includes the combination of several drugs. Therefore, it provides huge benefits in multi-medicated patients, such as the elderly. 3D extrusion printing have been successfully used to create different polypills, as example, captopril, nifedipine, and glipizide, to treat hypertension and type 2 diabetes, have been manufactured in a single pill by using 3D printing. The technology has moved forward and currently, prototypes including five different types of APIs with different release profiles have been produced [68]. Three medicines; pravastatin, atenolol, and ramipril; were included in the extendedrelease compartment where the drugs were physically separated by a permeable membrane of hydrophobic cellulose acetate. An immediate release compartment containing aspirin and hydrochlorothiazide was deposited on top of the fore mentioned compartment [69, 70].

\section{Microneedle design}

Microneedles are a kind of transdermal drug delivery system, which has arrays of micron-sized needles on the surface of a matrix to enhance the skin penetration of biologically active molecules. Microneedle can be categorized into two types; hollow microneedle, and solid microneedle. The hollow microneedle is designed to be used to deliver liquids such as medicines to the blood vessels, while, solid microneedle is intended to be similar to a lancet for drawing blood [71]. In design studies, there are a few parameters that can be considered, such as the height of the needle, shape of the needle, materials, and the tip. All the parameters needed to be analyzed before undergoing the fabrication process. Previously, microneedle is made up of silicon, metals, polymers, glass, and silicon dioxide through micro-electro-mechanical system(MEMS) technology. Despite that, the fabrication period using MEMS technology is too long due to many processes that should be conducted [72]. Nowadays, the 3D printer technology has upgraded in terms of its resolution and accuracy that allow the printer to print using many materials and sizes in micron. The printing size is suitable with the size of the microneedle. Hence, many researchers introduce the use of the $3 \mathrm{D}$ printers to fabricate microneedle, a Solid Works 2017 is used to design the microneedle. This study focuses on conical and pyramid design. In 2018, Luzuriaga et al. developed biodegradable microneedles by using a new technique called microfabrication, and FDM as 3D printer with improved resolution, demonstrating that the printing parameters could be tuned to create microneedles of various shapes, lengths, and array densities, without a master template [73].

\section{Preparation of rectal and vaginal delivery systems}

Rectal and vaginal drug delivery via suppositories, pessaries, intrauterine devices, and surgical stents are used to provide drugs for local and systemic therapeutic effects. Highly professional methods are required to manufacture these dosage forms by the conventional approach, where the resulting systems need to be able to precisely fit the patient's anatomy $[74,75]$. Accordingly, 3D printing was used to print such dosage forms by using a casting approach to produce suppositories and pessaries of castable resins and silicone polymers for the delivery of anti-inflammatory medicines. In another study, computer-aided designing modeling and prenatal ultrasound developed 3D printed personalized vaginal pessaries to identify the dimensional requirements for the treatment of stressful urinary incontinence showed improved therapeutic performance compared with conventional lines [76].

\section{D printing of responsive hydrogels}

Hydrogels, fabricated by 3D printing, can be defined as cross-linked network of hydrophilic polymers which can absorb a large amount of water or biological fluids by swelling. The hydrogels may respond to chemical and physical stimuli such as temperature, pressure, $\mathrm{pH}$, ionic strength, and magnetic or electric field [77]. Due to their biocompatibility and swelling capability in different stimuli, they can be used for drug-delivery systems for controlled drug release [78]. The $\mathrm{pH}$-responsive hydrogel tablets with complex structures and controlled release of drugs produced by digital light processing (DLP) printing technology. The technology is based on photopolymerization, enabled by DLP for curing photoreactive polymers [79]. The localized polymerization is performed within a bath filled with a polymerizable ink, usually by proper focusing of UV light. DLP allows high-resolution, low printing cost, and large build size [80].

Material considerations in discussing 3D printed
pharmaceuticals

It is also important to consider the type of material whether it be a powder, solid bulk, or liquefied substance that is used to print the drug product. SLS and binder deposition both require powder substance. Compatible with extrusion-based printing, fused deposition modeling (FDM) depends on the extrusion of solid filaments loaded with the desired drug. Due to the dependence on solid polymer-based filaments, this method poses more challenges in making it suitable for oral dosage medicines. Conversely, natural and synthetic hydrogels have a more viscous consistency that makes them more appropriate for oral drug products. Additionally, the viscous nature of hydrogels allows for extrusion-based or inkjetbased printing. To apply 3DP for drug delivery, it is mandatory to study the rheological properties of binder solution, especially when high-molecular-weight polymers are involved in dosage forms. In the powder deposition technique, polymers must be present in fine particles for the 3DP process. Thus the polymer which can be processed in fine particles can only be used in 3DP technology. The stair-stepping problem needs to be addressed in the powder deposition technique [81].

\section{Selection of polymers in 3D printing methods for drug delivery}

3D printer technology has progressed as a novel "biomedical technique". Polymers are the spine in the formulation of 3D printing dosage forms because they are responsible for modifying the release rate and enhance physical stability to incorporated active pharmaceutical ingredients. Polymers of natural and synthetic origin find applications for 3DP printing, natural polymers such as gelatin, collagen, alginate, and chitosan are usually utilized, but they frequently need cross-linkers which could be cytotoxic. Therefore, synthetic polymers have recently gained attention for 3D printing to avoid disadvantages associated with natural polymers.

Polymers currently exploited for various 3D technologies are thermoplastic polymers such as polyurethane, polystyrene, PVA, polyethylene glycol diacrylate, PLA, and poly lactide-co-glycolide, poly $\varepsilon$-caprolactone (PCL), polyamides, cellulose derivatives like ethyl cellulose and HPMC, and polymethyl acrylate (Eudragit) ${ }^{\circledR}$ polymers. Thermoplastic polymers are generally utilized in the fused deposition modeling methods, while any powdered polymers can be used in inkjet printing methods. Due to the utilization of high molecular weight thermoplastic polymer, FDM often leads to a prolonged-release pattern. The starting materials that could be used in SLA and SLS techniques are thermostable heat processable polymers such as polyamides, polystyrene, PLA, PVA, in addition to epoxy and acrylate-based resins [82]. 
Table 1: Examples of drugs fabricated by 3D printing technologies

\begin{tabular}{lll}
\hline Printer type/printing technique & Dosage forms/systems & Model drug used \\
\hline Fused-filament 3D printing & Tablets & Fluorescein \\
3D printer & Tablets & Paracetamol \\
3D printer & Tablet implant & Isoniazid \\
Fused deposition 3D printer & Immediate-release tablets & 5-Aminosalicylic acid, Captopril, \\
& & Theophylline and Prednisolone \\
Fused deposition 3D & printing Extended-release tablet & Prednisolone \\
Fused deposition 3D & Modified-release drug-loaded tablet & printer 5-Aminosalicylic acid and 4- \\
& & Aminosalicylic acid \\
3D printer & Complex matrix tablet with ethylcellulose & Acetaminophen \\
& gradients & \\
3D printer & Fast disintegrating tablet & Acetaminophen \\
Extrusion-based printer & Multi-active tablets (Polypill) & Captopril, Nifedipine and Glipizide \\
Inkjet printer & Implant with the lactic acid polymer matrix & Levofloxacin \\
3D printer & Complex oral dosage forms & Fluorescein \\
\hline
\end{tabular}

\section{CONCLUSION}

Although 3D printing technology showed promising results in drug delivery applications, the technology is still in the developing stage. 3D printing technology represents a great potential in drug development, formulation, and administration due to its great flexibility and efficacy in the innovation and creation of novel medical products. Besides, the suitability of the technology as a tool for drug individualization is massive given its ability to manipulate high degrees of drug deposition patterns to assess different release profiles. 3D printing technologies are working to alter pharmacy practice by allowing medications to be actually individualized and personalized specifically to each patient, although technical and regulatory difficulties remain.

\section{ACKNOWLEDGMENT}

The author is highly thankful to Dr. Mohammed Iqdam Mohammed Ridha, who inspired me to write this review.

\section{FUNDING}

Nil

\section{AUTHORS CONTRIBUTIONS}

All the work have been carried out by me.

\section{CONFLICT OF INTERESTS}

Declared none

\section{REFERENCES}

1. Jose PA, GV PC. 3D printing of pharmaceuticals-a potential technology in developing personalized medicine. Asian J Pharm Res Dev 2018;6:46-54.

2. Mathew E, Pitzanti G, Larraneta E, Lamprou DA. Threedimensional printing of pharmaceuticals and drug delivery devices. Pharmaceutics 2020;12:1-9.

3. Trenfield SJ, Awad A, Goyanes A, Gaisford S, Basit AW. 3D printing pharmaceuticals: drug development to frontline care. Trends Pharmacol Sci 2018;39:440-51.

4. Bhusnure OG, Gholve SV, Sugave BK, Dongre RC, Gore SA, Giram PS. 3D printing and pharmaceutical manufacturing: opportunities and challenges. Int J Bioassays 2016;5:4723-38.

5. Jamroz W, Szafraniec J, Kurek M, Jachowicz R. 3D printing in pharmaceutical and medical applications-recent achievements and challenges. Pharm Res 2018;35:1-22.

6. Xu X, Zhao J, Wang M, Wang L, Yang J. 3D printed polyvinyl alcohol tablets with multiple release profiles. Sci Rep 2019;9:1-8.

7. Adhitya L, Pradono S, Cholid B. Three-dimensional model printing in oral and maxillofacial reconstructive surgery: comparison of three-dimensional models and multislice computed tomography scans. Int J Appl Pharm 2017;9:1-5.

8. Samiei N. Recent trends on applications of 3D printing technology on the design and manufacture of pharmaceutical oral formulation: a mini-review. Beni Suef Univ J Basic Appl Sci 2020;9:1-12.
9. Mazhar M, Tariq U. A review "three-dimensional (3d) drug printing: a revolution in pharmaceutical science. PharmaTutor 2019;7:19-25.

10. Wang J, Goyanes A, Gaisford S, Basit AW. Stereolithographic (SLA) 3D printing of oral modified-release dosage forms. Int J Pharm 2016;503:207-12.

11. Prasad LK, Smyth H. 3D Printing technologies for drug delivery: a review. Drug Dev Ind Pharm 2016;42:1019-31.

12. Jamroz W, Szafraniec J, Kurek M, Jachowicz R. 3D printing in pharmaceutical and medical applications-recent achievements and challenges. Pharm Res 2018;35:1-22.

13. TU, MM. Three-dimensional (3D) drug printing: a revolution in pharmaceutical science. PharmaTutor 2019;7:19.

14. Vithani K, Goyanes A, Jannin V, Basit AW, Gaisford S, Boyd BJ. An overview of 3D printing technologies for soft materials and potential opportunities for lipid-based drug delivery systems. Pharm Res 2019;36:1-20.

15. Sandler N, Preis M. Printed drug-delivery systems for improved patient treatment. Trends Pharmacol Sci 2016;37:1070-80.

16. Samiei N. Recent trends on applications of 3D printing technology on the design and manufacture of pharmaceutical oral formulation: a mini-review. Beni-Suef Univ J Basic Appl Sci 2020;9:1-12.

17. Alhnan MA, Okwuosa TC, Sadia M, Wan KW, Ahmed W, Arafat B. Emergence of 3D printed dosage forms: opportunities and challenges. Pharm Res 2016;33:1817-32.

18. Pravin S, Sudhir A. Integration of 3D printing with dosage forms: a new perspective for modern healthcare. Biomed Pharmacother 2018;107:146-54.

19. Souto EB, Campos JC, Filho SC, Teixeira MC, Martins Gomes C, Zielinska A, et al. 3D printing in the design of pharmaceutical dosage forms. Pharm Dev Technol 2019;24:1044-53.

20. Ponni RT, Swamivelmanickam M, Sivakrishnan S. 3D printing in pharmaceutical technology-a review. Int J Pharm Investig 2020;10:8-12.

21. Anand N, Singh D, Singh G, Kaur L, Dhawan RK, Kaur N. 3D printing technology in pharmaceutical delivery system: recent advancement in innovative approach. FABAD J Pharm Sci 2020;45:253-68.

22. Buanz ABM, Saunders MH, Basit AW, Gaisford S. Preparation of personalized-dose salbutamol sulfate oral films with thermal ink-jet printing. Pharm Res 2011;28:2386-92.

23. Melendez PA, Kane KM, Ashvar CS, Albrecht M, Smith PA. Thermal inkjet application in the preparation of oral dosage forms: dispensing of prednisolone solutions and polymorphic characterization by solid-state spectroscopic techniques. J Pharm Sci 2008;97:2619-36.

24. Ian Gibson IG. Additive manufacturing technologies 3D printing, rapid prototyping, and direct digital manufacturing. $2^{\text {nd }}$ edition. Springer; 2015.

25. Vaz VM, Kumar L. 3D printing as a promising tool in personalized medicine. AAPS PharmSciTech 2021;22:1-20.

26. Haris MS, Azlan NHM, Taher M, Rus SM, Chatterjee B. 3D-printed drugs: a fabrication of pharmaceuticals towards personalized medicine. Int J Pharm Edu Res 2020;54:S411-S422. 
27. Tian Y, Orlu M, Woerdenbag HJ, Scarpa M, Kiefer O, Kottke D, et al. Oromucosal films: from patient centricity to production by printing techniques. Expert Opin Drug Delivery 2019;16:981-93.

28. Goyanes A, Buanz ABM, Hatton GB, Gaisford S, Basit AW. 3D printing of modified-release aminosalicylate (4-ASA and 5ASA) tablets. Eur J Pharm Biopharm 2015;89:157-62.

29. Monisha B, Varun S, Gurfateh S, SL Harikumar. 3D printing for the future of pharmaceuticals dosages forms. Int J Appl Pharm 2018;10:1-7.

30. Goole J, Amighi K. 3D printing in pharmaceutics: a new tool for designing customized drug delivery systems. Int J Pharm 2016;499:376-94.

31. Wen H, He B, Wang H, Chen F, Li P, Cui M, et al. Structure-based gastro-retentive and controlled-release drug delivery with novel 3D printing. AAPS PharmSciTech 2019;20:1-12.

32. Okafor Muo OL, Hassanin H, Kayyali R, ElShaer A. 3D printing of solid oral dosage forms: numerous challenges with unique opportunities. J Pharm Sci 2020;109:3535-50.

33. Melchels FPW, Feijen J, Grijpma DW. A review on stereolithography and its applications in biomedical engineering. Biomaterials 2010;31:6121-30.

34. Melchels FPW, Feijen J, Grijpma DW. A poly (D, L-lactide) resin for the preparation of tissue engineering scaffolds by stereolithography. Biomaterials 2009;30:3801-9.

35. Martinez PR, Goyanes A, Basit AW, Gaisford S. Fabrication of drug-loaded hydrogels with stereolithographic 3D printing. Int J Pharm 2017;532:313-7.

36. Fina F, Gaisford S, Basit AW. Powder bed fusion: the working process, current applications and opportunities. In: 3D printing of pharmaceuticals. Springer; 2018. p. 81-105.

37. Yuan S, Shen F, Chua CK, Zhou K. Polymeric composites for powder-based additive manufacturing: materials and applications. Prog Polym Sci 2019;91:141-68.

38. Allahham N, Fina F, Marcuta C, Kraschew L, Mohr W, Gaisford S, et al. Selective laser sintering 3D printing of orally disintegrating printlets containing ondansetron. Pharmaceutics 2020;12:110.

39. Zhang J, Hu Q, Wang S, Tao J, Gou M. Digital light processing based three-dimensional printing for medical applications. Int J Bioprinting 2020;6:1-16.

40. Madzarevic M, Medarevic D, Vulovic A, Sustersic T, Djuris J, Filipovic $\mathrm{N}$, et al. Optimization and prediction of ibuprofen release from 3D DLP printlets using artificial neural networks. Pharmaceutics 2019;11:1-16.

41. Krkobabic M, Medarevic D, Pesic N, Vasiljevic D, Ivkovic B, Ibric S. Digital light processing (DLP) 3D printing of atomoxetine hydrochloride tablets using photoreactive suspensions. Pharmaceutics 2020;12:1-17.

42. Hemanth KG, Hemamanjushree S, Abhinaya N, Pai R, Pai G. 3D Printing: a review on technology, role in novel dosage forms and regulatory perspective. Res J Pharm Technol 2021;14:562-72.

43. Murphy SV, Atala A. 3D bioprinting of tissues and organs. Nat Biotechnol 2014;32:773-85.

44. Nandi S. 3D printing of pharmaceuticals-leading trend in pharmaceutical industry and future perspectives. Asian J Pharm Clin Res 2020;13:10-6.

45. Rycerz K, Stepien KA, Czapiewska M, Arafat BT, Habashy R, Isreb A, et al. Embedded 3D printing of novel bespoke soft dosage form concept for pediatrics. Pharmaceutics 2019;11:1-15.

46. Mathew E, Pitzanti G, Larraneta E, Lamprou DA. 3D printing of pharmaceuticals and drug delivery devices. Pharmaceutics 2020;12:1-9.

47. Haris MS, Azlan NHM, Taher M, Rus SM, Chatterjee B. 3D-printed drugs: a fabrication of pharmaceuticals towards personalized medicine. Indian J Pharm Educ Res 2020;54:S411-22.

48. Zema L, Melocchi A, Maroni A, Gazzaniga A. Three-dimensional printing of medicinal products and the challenge of personalized therapy. J Pharm Sci 2017;106:1697-705.

49. Pietrzak K, Isreb A, Alhnan MA. A flexible-dose dispenser for immediate and extended release 3D printed tablets. Eur J Pharm Biopharm 2015;96:380-7.

50. Awad A, Fina F, Trenfield SJ, Patel P, Goyanes A, Gaisford S, et al. 3D printed pellets (miniprintlets): a novel, multi-drug, controlled release platform technology. Pharmaceutics 2019;11:148.
51. Keerthi ML, Kiran RS, Rao VUM, Sannapu A, Dutt AG, Krishna KS. Evaluation aspects: a review multi unit dosage forms. Int J Pharm 2014;28:214-21.

52. Liang $\mathrm{K}$, Brambilla $\mathrm{D}$, Leroux J. Is 3D printing of pharmaceuticals a disruptor or enabler? Adv Mater 2019;31:1805680.

53. Trenfield SJ, Madla CM, Basit AW, Gaisford S. Binder jet printing in pharmaceutical manufacturing. In: 3D printing of pharmaceuticals. Springer; 2018. p. 41-54.

54. Palekar S, Nukala PK, Mishra SM, Kipping T, Patel K. Application of 3D printing technology and quality by design approach for development of age-appropriate pediatric formulation of baclofen. Int J Pharm 2019;556:106-16.

55. Scoutaris N, Ross SA, Douroumis D. 3D printed "Starmix" drug loaded dosage forms for paediatric applications. Pharm Res 2018;35:1-11.

56. Goyanes A, Madla CM, Umerji A, Pineiro GD, Montero JMG, Diaz $\mathrm{MJL}$, et al. Automated therapy preparation of isoleucine formulations using 3D printing for the treatment of MSUD: first single-centre, prospective, crossover study in patients. Int J Pharm 2019;567:118497.

57. Ispas Szabo P, Friciu MM, Nguyen P, Dumoulin Y, Mateescu MA. Novel self-assembled mesalamine-sucralfate complexes: preparation, characterization, and formulation aspects. Drug Dev Ind Pharm 2016;42:1183-93.

58. Yu DG, Branford White C, Ma ZH, Zhu LM, Li XY, Yang XL. Novel drug delivery devices for providing linear release profiles fabricated by 3DP. Int J Pharm 2009;370:160-6.

59. Liang K, Carmone S, Brambilla D, Leroux JC. 3D printing of a wearable personalized oral delivery device: a first-in-human study. Sci Adv 2018;4:eaat 2544.

60. Lim SH, Kathuria H, Tan JJY, Kang L. 3D printed drug delivery and testing systems-a passing fad or the future? Adv Drug Delivery Rev 2018;132:139-68.

61. Choonara YE, du Toit LC, Kumar P, Kondiah PPD, Pillay V. 3Dprinting and the effect on medical costs: a new era? Expert Rev Pharmacoecon Outcomes Res 2016;16:23-32.

62. Khaled SA, Burley JC, Alexander MR, Roberts CJ. Desktop 3D printing of controlled release pharmaceutical bilayer tablets. Int J Pharm 2014;461:105-11.

63. Zhu X, Li H, Huang L, Zhang M, Fan W, Cui L. 3D printing promotes the development of drugs. Biomed Pharmacother 2020;131:110644.

64. Chai X, Chai H, Wang X, Yang J, Li J, Zhao Y, et al. Fused deposition modeling (FDM) 3D printed tablets for intragastric floating delivery of domperidone. Sci Rep 2017;7:1-9.

65. Kurzrock R, Stewart DJ. Click chemistry, 3D-printing, and omics: the future of drug development. Oncotarget 2016;7:2155.

66. Islam R, Sadhukhan P. An insight of 3d printing technology in pharmaceutical development and application: an updated review. Curr Trends Pharm Res 2020;7:1-26.

67. Goyanes A, Det-Amornrat U, Wang J, Basit AW, Gaisford S. 3D scanning and 3D printing as innovative technologies for fabricating personalized topical drug delivery systems. J Controlled Release 2016;234:41-8.

68. Huffman MD, Xavier D, Perel P. Uses of polypills for cardiovascular disease and evidence to date. Lancet 2017;389:1055-65.

69. Konta AA, Garcia Pina M, Serrano DR. Personalised 3D printed medicines: which techniques and polymers are more successful? Bioengineering 2017;4:1-16.

70. Webster R, Castellano JM, Onuma OK. Putting polypills into practice: challenges and lessons learned. Lancet 2017;389:1066-74.

71. Dabbagh SR, Sarabi MR, Rahbarghazi R, Sokullu E, Yetisen AK, Tasoglu S. 3D-printed microneedles in biomedical applications. iScience 2021;24:102012.

72. Krieger KJ, Bertollo N, Dangol M, Sheridan JT, Lowery MM, O'Cearbhaill ED. Simple and customizable method for fabrication of high-aspect ratio microneedle molds using lowcost 3D printing. Microsystems Nanoeng 2019;5:1-14.

73. Park BJ, Choi HJ, Moon SJ, Kim SJ, Bajracharya R, Min JY, et al. Pharmaceutical applications of 3D printing technology: current understanding and future perspectives. J Pharm Investig 2019;49:575-85. 
74. Xu X, Zhao J, Wang M, Wang L, Yang J. 3D printed polyvinyl alcohol tablets with multiple release profiles. Sci Rep 2019;9:1-8.

75. Tagami T, Hayashi N, Sakai N, Ozeki T. 3D printing of unique water-soluble polymer-based suppository shell for controlled drug release. Int J Pharm 2019;568:118494.

76. Genina N, Hollander J, Jukarainen H, Makila E, Salonen J, Sandler N. Ethylene vinyl acetate (EVA) as a new drug carrier for 3D printed medical drug delivery devices. Eur J Pharm Sci 2016;90:53-63.

77. Rao KSVK, Ha CS. pH Sensitive hydrogels based on acryl amides and their swelling and diffusion characteristics with drug delivery behavior. Polym Bull 2009;62:167-81.

78. Ahmed EM. Hydrogel: preparation, characterization, and applications: a review. J Adv Res 2015;6:105-21.

79. Rizwan M, Yahya R, Hassan A, Yar M, Azzahari AD, Selvanathan $\mathrm{V}$, et al. pH sensitive hydrogels in drug delivery: brief history, properties, swelling, and release mechanism, material selection and applications. Polymers (Basel) 2017;9:1-37.

80. Patel DK, Sakhaei AH, Layani M, Zhang B, Ge Q, Magdassi S. Highly stretchable and UV curable elastomers for digital light processing based 3D printing. Adv Mater 2017;29:1606000.

81. Norman J, Madurawe RD, Moore CMV, Khan MA, Khairuzzaman A. A new chapter in pharmaceutical manufacturing: 3D-printed drug products. Adv Drug Delivery Rev 2017;108:39-50.

82. Jacob S, Nair AB, Patel V, Shah J. 3D printing technologies: recent development and emerging applications in various drug delivery systems. AAPS PharmSciTech 2020;21:1-16.

83. Goyanes A, Buanz ABM, Basit AW, Gaisford S. Fused-filament 3D printing (3DP) for fabrication of tablets. Int J Pharm 2014;476:88-92.
84. Goyanes A, Martinez PR, Buanz A, Basit AW, Gaisford S. Effect of geometry on drug release from 3D printed tablets. Int J Pharm 2015;494:657-63.

85. Wu G, Wu W, Zheng Q, Li J, Zhou J, Hu Z. Experimental study of PLLA/INH slow release implant fabricated by three dimensional printing technique and drug release characteristics in vitro. Biomed Eng Online 2014;13:1-11.

86. Sadia M, Sosnicka A, Arafat B, Isreb A, Ahmed W, Kelarakis A, et al. Adaptation of pharmaceutical excipients to FDM 3D printing for the fabrication of patient-tailored immediate release tablets. Int J Pharm 2016;513:659-68.

87. Skowyra J, Pietrzak K, Alhnan MA. Fabrication of extendedrelease patient-tailored prednisolone tablets via fused deposition modelling (FDM) 3D printing. Eur J Pharm Sci 2015;68:11-7.

88. Yu DG, Yang XL, Huang WD, Liu J, Wang YG, Xu H. Tablets with material gradients fabricated by three-dimensional printing. J Pharm Sci 2007;96:2446-56.

89. Yu DG, Branford White C, Yang YC, Zhu LM, Welbeck EW, Yang XL. A novel fast disintegrating tablet fabricated by threedimensional printing. Drug Dev Ind Pharm 2009;35:1530-6.

90. Khaled SA, Burley JC, Alexander MR, Yang J, Roberts CJ. 3D printing of tablets containing multiple drugs with defined release profiles. Int J Pharm 2015;494:643-50.

91. Huang W, Zheng Q, Sun W, Xu H, Yang X. Levofloxacin implants with predefined microstructure fabricated by threedimensional printing technique. Int J Pharm 2007;339:33-8.

92. Katstra WE, Palazzolo RD, Rowe CW, Giritlioglu B, Teung P, Cima MJ. Oral dosage forms fabricated by three dimensional printing ${ }^{\mathrm{TM}}$. J Controlled Release 2000;66:1-9. 